\title{
Stablecoins: risks, potential and regulation
}

Douglas Arner, Raphael Auer and Jon Frost (*)

$\left(^{*}\right)$ Douglas Arner, Kerry Holdings Professor in Law, University of Hong Kong, douglas.arner@hku.hk; Raphael Auer, Principal Economist, Innovation and the Digital Economy, Bank for International Settlements (BIS), raphael.auer@bis.org; Jon Frost, Senior Economist, Innovation and the Digital Economy, BIS, jon.frost@bis.org. This article is the sole responsibility of the authors and does not necessarily reflect the opinion of the Banco de España, the Eurosystem or the BIS. All errors are our own. We thank Stijn Claessens, Leonardo Gambacorta, Antony Lewis, Tony McLaughlin, Bénédicte Nolens, Joe Noss, Tara Rice, Lee Schneider, Hyun Song Shin, Nobu Sugimoto, Andres Wolberg-Stok, Dirk Zetzsche and an anonymous referee for comments, and thank Giulio Cornelli for research assistance as well as María Luisa Leyva for editorial support. Douglas Arner thanks the Hong Kong Research Grants Council Research Impact Fund for financial support. 

Abstract

The technologies underlying money and payment systems are evolving rapidly. Both the emergence of distributed ledger technology (DLT) and rapid advances in traditional centralised systems are moving the technological horizon of money and payments. These trends are embodied in private "stablecoins": cryptocurrencies with values tied to fiat currencies or other assets. Stablecoins - in particular potential "global stablecoins" such as Facebook's Libra proposal - pose a range of challenges from the standpoint of financial authorities around the world. At the same time, regulatory responses to global stablecoins should take into account the potential of other stablecoin uses, such as embedding a robust monetary instrument into digital environments, especially in the context of decentralised systems. Looking forward, in such cases, one possible option from a regulatory standpoint is to embed supervisory requirements into stablecoin systems themselves, allowing for "embedded supervision". Yet it is an open question whether central bank digital currencies (CBDCs) and other initiatives could in fact provide more effective solutions to fulfil the functions that stablecoins are meant to address.

\section{Introduction}

Finance and technology have always been co-developmental, with global trends in digitisation and datafication transforming finance over the past several decades. ${ }^{1}$ The 2010s, however, ushered in a burst of energy around digital innovation in finance, emanating from rapidly evolving technologies, particularly information and communications technologies (ICT). These innovations have affected not only financial services like payments, credit, investment and insurance, but also the core foundations of the financial system - namely money - itself [BIS (2018 and 2020)]. The COVID-19 crisis has accelerated the shift to digital payments. It has fanned public concerns about viral transmission through cash (see Chart 1.1) and led to a surge in the use of digital payments [Auer et al. (2020a)] (see Chart 1.2).

As with all periods of rapid innovation, there is the potential for excessive hype, fads and hyperbole, as highlighted in the classic financial instability hypothesis [Fisher (1933), Minsky (1975 and 1982) and Kindleberger (1978)] or the more

1 Digitisation can be defined as the process of changing information from analogue to digital form. This is sometimes confused with digitalisation - the use of digital technologies to change a business model and provide new revenue and value-producing opportunities, or the process of moving to a digital business. See Gartner (2020). Datafication, meanwhile, refers to the collective tools, technologies, and processes used to transform an organisation into a data-driven enterprise. 
Chart 1

\section{CONCERNS ABOUT VIRAL TRANSMISSION BY CASH HAVE ACCELERATED THE SHIFT TO DIGITAL PAYMENTS}

The shaded areas in Chart 1.1 indicate Jan 2009-Aug 2010 [Swine Flu (H1N1)], Sep 2012-Mar 2016 [Middle East Respiratory Syndrome Coronavirus (MERS-CoV)], Dec 2013-Mar 2016 (West African Ebola epidemic) and Dec 2019-current (COVID-19). The black vertical line in Chart 1.2 indicates 30 January 2020, when the World Health Organisation (WHO) declared the COVID-19 outbreak a "public health emergency of international concern".
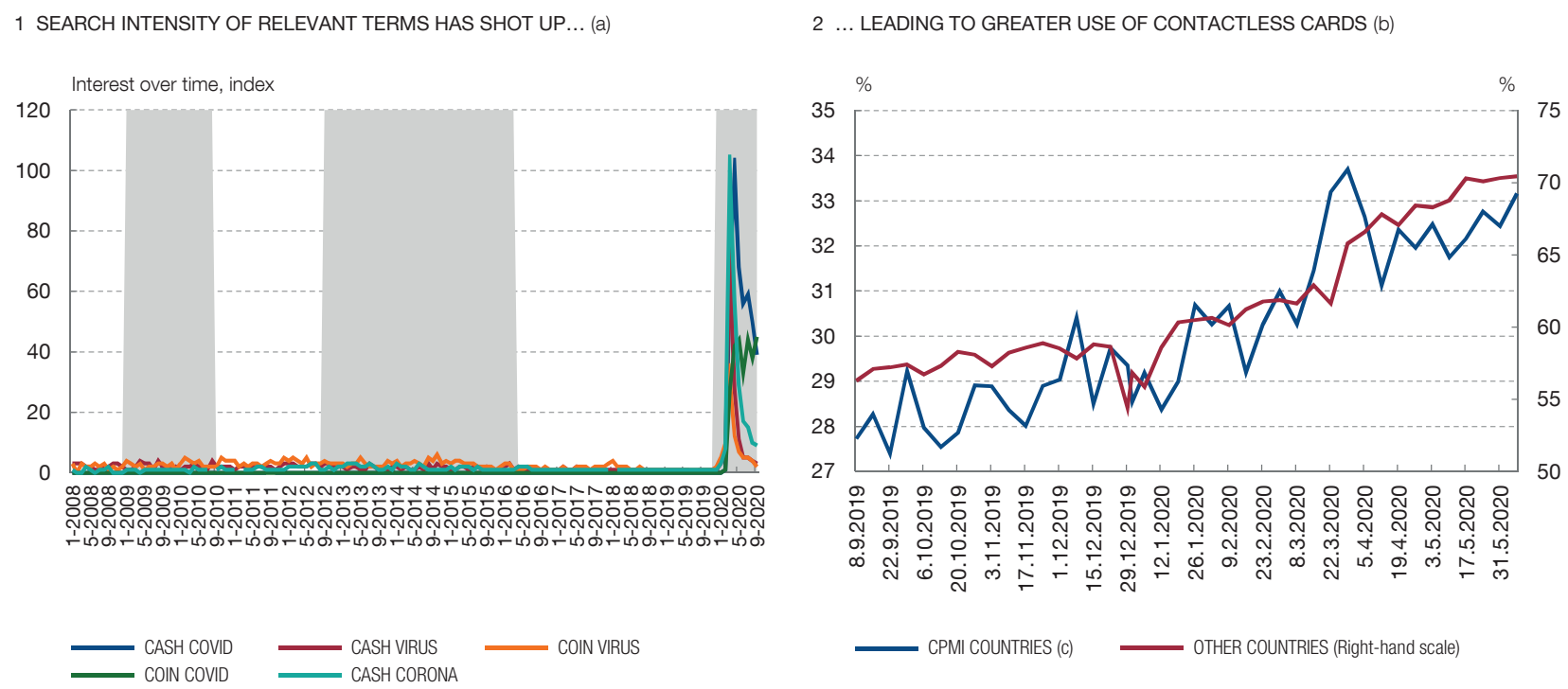

SOURCES: Auer et al. (2020a), BIS (2020) and Google Trends.

a Data accessed on 21 Mar 2020. Data resulting from worldwide Google search queries for selected terms in the period 2008-current, indexed to 100 by peak search interest.

b Share of contactless in all card-present transactions by a global card network. In many countries, transaction limits for contactless payments were raised in Q2 2020.

c Countries that are members of the Committee on Payments and Market Infrastructures (CPMI). Excludes MX and TR due to data availability.

contemporary Gartner hype cycle [Gartner (2020)]. For authorities and the public alike, separating the "wheat from the chaff" in digital innovation remains a challenge. Just as Paul Volcker questioned the value of past financial innovations in the aftermath of the 2008 Great Financial Crisis [WSJ (2009)], future observers may look back sceptically on some current digital innovations. For central banks and regulators, these challenges take on particular importance in their pursuit of financial and monetary stability.

Today, authorities around the world are grappling with the rise of digital currencies and decentralised finance based on both emerging technologies - particularly various combinations of distributed ledger technology (DLT) and blockchain ${ }^{2}-$ and

2 The term "blockchain" is often used interchangeably with systems which are often based on a combination of DLT and blockchain, in which blockchain is in fact a cryptographic security structure. While it is often used with DLT, it can in fact be used in the context of permissionless, permissioned DLT and even in centralised systems, in which blocks of transactions are encrypted together. For a discussion of the spectrum of different types of DLT, see Wadsworth (2018). 
advances in traditional centralised systems underpinning finance. Many argue that a technological revolution is occurring in money and payment systems [Arner et al. (2020)]. From the creation of Bitcoin in 2009, to the emergence of "stablecoin" projects such as Dai, HUSD, Paxos Standard, Tether, TrueUSD and USD Coin starting from 2014, to the announcement of Facebook's Libra project in 2019, technological challenges to existing monetary frameworks have put a broader set of regulatory issues on the agenda [see Fatás and Weder di Mauro (2019), G7 Working Group on Stablecoins (2019) and FSB (2020)]. An overarching consideration is that, when faced with innovations, authorities must consider how best to apply regulation so that similar economic and financial risks emerging from varying technologies and participants are treated similarly, avoiding regulatory arbitrage. Still, the "regulatory dialectic" of regulation, regulatory avoidance and re-regulation [Kane (1977 and 1981)] may be unavoidable.

While Bitcoin and other cryptocurrencies have not evolved into major alternatives to sovereign monetary arrangements, stablecoins have raised new challenges. They also offer opportunities for specific use cases, with private stablecoins aiming to be adopted as a means of payment for online purchases ("e-commerce"), peer-to-peer and micro-payments and a range of potential future applications. As discussed further below, they also have the potential to serve as a digital monetary instrument to embed in DLT applications, including for programmable money or smart contracts.

In the current policy debate, a stablecoin can be defined as a cryptocurrency that aims to maintain a stable value relative to a specified asset, or a pool or basket of assets [FSB (2020)]. ${ }^{3}$ Following the "money flower" of Bech and Garratt (2017), stablecoins inhabit the same realm as Bitcoin and other cryptocurrencies, in that they are electronic, can be exchanged peer-to-peer and are not issued by central banks. Stablecoins are token-based; their validity is verified based on the token, itself, rather than the identity of the counterparty, as is the case for account-based payments [see Kahn (2016)].

The idea of stablecoins is not entirely new. Indeed, one can argue that early European public deposit banks, such as the 17th century Bank of Amsterdam, shared an economic structure with modern stablecoin proposals [Frost et al. (2020), Carstens (2019) and Knot (2019)]. Stored value cards and money market funds (MMFs) also offer some parallels, as do various forms of mobile money, with discussions of electronic or "e-money" dating to the 1990s. Yet DLT has allowed for the creation of new digital forms of money and payment systems that could serve novel purposes and extend some of the well-known economic and regulatory issues with past innovations into the digital realm. Existing stablecoins such as Tether, USD Coin and Maker's

3 The FSB and other international policy committees refer to cryptocurrencies as "crypto-assets" to emphasise that they are not currencies. In this paper, we will use the two terms synonymously. 
Dai, aim to serve as a means of settlement for automated financial products. They offer also offer the possibility of so-called "smart" contracts, i.e. self-executing code, and possibilities for "programmable money". ${ }^{4}$ Stablecoin proposals like Libra claim that they will make possible new forms of online exchange through their 24/7 availability, borderless nature, fractionalisation ${ }^{5}$ and integration with non-financial services. In this light, they aim to challenge existing digital means of payment for e-commerce like traditional bank payments, credit cards and electronic wallets.

The market value of existing stablecoins (Tether, USD Coin, Dai, etc.) reached USD 14 bn in August 2020, yet authorities are braced for a world in which these volumes are orders of magnitude higher. If this comes to pass, regulation and supervision will need to adapt quickly, both to monitor and assess risks from stablecoins, and to address risks to the economy, consumers and the financial system. Facebook's announcement of its Libra project has taken the private stablecoin onto an entirely different plane than any previous cryptocurrency or stablecoin: it is the first proposal backed by a group of corporations for a "global stablecoin" aimed at retail payments. ${ }^{6}$ Also with the changes introduced in Libra 2.0 [see Libra Association (2020)], this project involves the creation of both a new stablecoin with both existing and new payment systems. The Libra stablecoin in particular could be used across Facebook's rapidly growing payments offerings in multiple markets including Facebook Pay, WhatsApp Pay and Instagram Pay, with potentially rapid access to hundreds of millions of retail customers in a very short period. If successful, Libra could easily attain mass adoption across multiple jurisdictions given the established networks of Facebook and other Libra Association members, with the potential to achieve substantial volumes relative to the existing payments providers. This could bring a range of benefits, particularly in the context of cross-border transfers, but it also raises substantial questions for monetary and financial authorities.

The fact that regulation should treat similar risks arising from differing technologies similarly does not preclude public authorities themselves from embracing innovation. Authorities are applying technology in their own functions, whether in the context of regulation and supervision or in the provision of public goods. These public goods include appropriate monetary instruments (constantly evolving with technology) and supporting payment and liquidity infrastructures. Whereas "financial regulation" is the process of setting the rules that apply to the regulated entities, "financial supervision" is the compliance monitoring and enforcement of these rules, which has to be dynamic and adaptable. In particular, technology opens up new possibilities

4 Smart contracts can be formally defined as programmable distributed applications that trigger financial flows or changes of ownership if specific events occur [FSB (2017)]. In other words, they are algorithms that automate the execution of contracts. Programmable money is not precisely defined in the literature, but generally refers to a similar set of applications that make automated payments conditional on certain objective criteria. See Section 2.

5 Fractionalisation refers here to the ability to pay in very small units, e.g. small fractions of one cent.

6 Global stablecoins are those that can build on existing large, cross-border user bases to scale rapidly and achieve substantial (global) volume. See G7 Working Group on Stablecoins (2019) and FSB (2020). 
to develop better forms of financial infrastructure, enhance supervisory processes and regulatory outcomes, and even for embedded supervision [Auer (2019b) and Arner et al. (2017)].

Stablecoin proposals are one area where embedded supervision may work in practice. Information is a central function of regulation, both from the standpoint of enhancing market functioning and efficiency, and as from the standpoint of supervision, whether for purposes of market integrity, customer and investor protection, or prudential supervision. Direct automated provision of data as a licensing or registration requirement for digital payment systems and markets provides an important opportunity to better use technology to achieve regulatory and supervisory objectives as well as reduce costs for market participants. While many DLT companies have not necessarily focused on this joining of technology, regulation and supervision, it is being seen in some contexts. The automated provision of information by certain large value digital payments platforms, such as Alipay and WeChat Pay in China, provides one example.

At the same time, there are open questions as to whether central bank digital currencies (CBDCs) and other initiatives could fulfil these functions even more effectively than privately developed stablecoins. CBDCs would enjoy the backing of the central bank and would not be subject to the same conflicts of interest around the asset backing and stabilisation mechanism. Their value could be fixed by design to the currency they reference (in particular in systems where the CBDC was actually the digital representation of the currency), thus eliminating fluctuations in value. The question is how a CBDC could be designed to offer robust interoperability with novel decentralised financial solutions [see Auer and Böhme (2020) for a taxonomy of technological designs].

Meanwhile, a number of improvements to existing payment systems could be an alternative or complement to both stablecoins and CBDCs. In particular, appropriately designed public sector and public-private initiatives, like retail fast payment systems (FPS), supported by public digital identify (ID) infrastructures, are already greatly improving the speed, availability and universal access of payments in many countries. In theory, FPS could offer additional functionalities or become interoperable with DLT applications. These could help to achieve some of the same policy goals.

This paper is organised as follows. Section 2 discusses extant stablecoins and stablecoin proposals, and means for monitoring them, including indicators on price volatility, volumes, use and economic potential. Section 3 discusses the specific case of Facebook's Libra, in particular its latest incarnation (“Libra 2.0"). Section 4 discusses principles for regulating stablecoins, in particular regarding financial stability and conflicts of interest around their asset backing. Section 5 discusses the promise of embedded supervision in the context of stablecoins, CBDCs and other financial technology frameworks. Section 6 concludes. 


\section{The stablecoin sector and how to monitor it}

Like the proverbial phoenix, stablecoins have risen from the ashes of the 2018 cryptocurrency bubble. After its introduction in 2009, Bitcoin saw at least two distinct periods of boom and bust - first in late 2013/early 2014, ending with the high-profile hack of crypto-exchange Mt. Gox, and second in late 2017/early 2018, when the market capitalisation of Bitcoin, Ether and other crypto-assets peaked at USD 830 bn before crashing. After the latest high-profile speculative bubble, it became clear that the high price volatility of existing cryptocurrencies impaired their usability as a means of payment, store of value or unit of account. ${ }^{7}$ As such, attention moved to a new type of digital asset which sought a stable value against one or more fiat currencies and/or other assets. Stablecoins like Tether (introduced in January 2014), USD Coin, Dai and others entered the limelight. However, it was the announcement of Facebook's Libra proposal in June 2019 which for the first time offered a stablecoin with serious potential to emerge as a monetary alternative with scale - the first so -called "global stablecoin" (see next section).

Stablecoins aim to preserve a stable value through at least two distinct mechanisms. Most commonly, stablecoin issuers purport to back stablecoins with fiat currency, assets or other cryptocurrencies; these are called asset-linked stablecoins. By contrast, algorithm-based stablecoins seek to use algorithms to increase or decrease the supply of stablecoins in response to changes in demand [FSB (2020)].

Initially, stablecoins evolved in order to address the failure of Bitcoin and other cryptocurrencies to provide an effective monetary and payment instrument. This reflected the preference of main market participants to base transactions and payments on sovereign fiat currencies, in particular the US dollar. It also reflected weaknesses in Bitcoin and other crypocurrencies inter alia as means of payment, store of value or unit of account. However, as no digital form of the dollar or other sovereign fiat currencies was available, market participants developed the stablecoin structure as a means to address this issue, as well as to provide an instrument to support hedging between crypto-assets and fiat currencies. The need was for a bridge between DLT and fiat currencies, with stablecoins seeking to fill this need. This was particularly relevant in the context of high volatility in the price of Bitcoin, making it less useful as a payment instrument and more of an investment-speculative or otherwise - or hedge. For instance, Tether claims to provide "individuals and organizations with a robust and decentralized method of exchanging value while using a familiar accounting unit" [Tether (2016)]. Tether has become a common means of putting funds into and out of crypto trading platforms. Issuers have also portrayed stablecoins as a solution to promote financial inclusion and address issues in cross-

7 The lack of scalability and high costs of achieving payment finality with permissionless DLT based on "proof-ofwork" are also barriers to adoption. Second-layer solutions such as the Lightning Network aim to enhance efficiency, yet the only fundamental remedy may be to depart from proof-of-work [Auer (2019a)]. 
border payments, particularly for emerging markets: this is in fact the central proposition initially put forward in the context of Libra [Libra Association (2019)].

Beyond these use cases, a range of new DLT/blockchain applications would benefit from a trustworthy monetary and payment instrument to embed in digital environments. For instance, many DLT projects aim to combine a digital environment and a monetary or payment instrument. In the context of decentralised systems, i.e. financial systems without formal intermediaries, a representation of value is very useful in designing smart contracts. One large example is Ethereum - a digital environment and infrastructure built on a dedicated digital token (Ether). In each case, however, the volatility of the underlying crypto-asset has been a major barrier for effective settlement. This has spurred the desire for a means to effectively link digital transactions with fiat currencies, and the case for stablecoins.

If successful, stablecoins could be a means to simplify and enable novel forms of exchange in the digital economy. For instance, smart contracts could allow for the automation of certain transactions - such as only transferring the funds for a house purchase once an inspection report has been received and confirmed. The financial transfer is thus automated on the basis of certain objective conditions, which trigger payment. The digital payment would be linked to fiat currency and accounts via the stablecoin. Decentralised transactions could enhance the efficiency of wholesale payments and settlement, trade finance and capital market transactions [FSB (2019)]. ${ }^{8}$ In such transactions, embedding payment into the transaction has the potential to both reduce risk (particularly payment and settlement risks) as well as enhance efficiency. Smart contracts could also execute micro-payments in the socalled "Internet of Things", such as self-driving cars that pay one another to change lanes when one is in a hurry and traffic is particularly heavy, or computers that pay one another for file storage space or processing power [see Milkau (2018)]. Governments could use "programmable money" in the form of stablecoins to restrict the purposes that government-to-person payments could be used for, such as only groceries, or making such funds "expire" after a certain period. ${ }^{9}$ Of course, this could also be done in the context of CBDCs or even "synthetic" CBDC structures, i.e. arrangements in which a private intermediary's digital token is directly backed with central bank reserves or liquidity facilities [see Auer et al. (2020b)]. Finally, because of their $24 / 7$ availability, borderless nature and fractionalisation, i.e. their ability to support programmable micropayments [McLaughlin (2020)], stablecoins could become a convenient digital means of payment for e-commerce. Particularly when integrated into online platforms, they could challenge current means of

8 Decentralisation of financial services refers to the elimination - or reduction in the role - of intermediaries or centralised processes. This may include the decentralisation of risk-taking, decision-making and record-keeping away from traditional intermediaries. See FSB (2019).

9 Experiments to date show that programmable money can also be used for more prosaic purposes. Feltwell et al. (2019) show the sometimes fanciful ideas of consumers, such as paying money into a penalty jar when personal resolutions not to eat junk food are broken, or adding money to a savings account when the International Space Station passes overhead. 


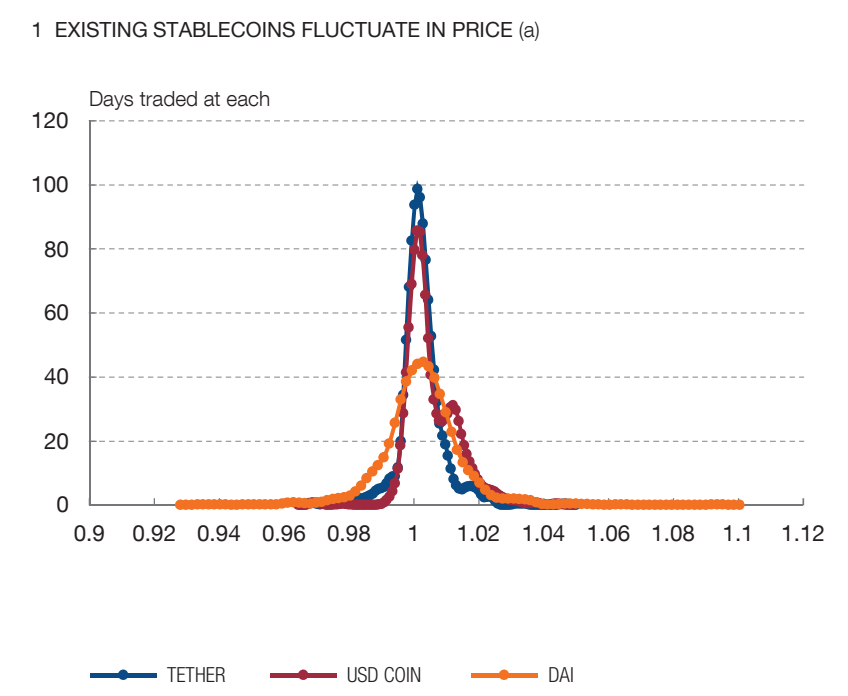

2 MARKET CAPITALISATIONS HAVE GROWN STRONGLY

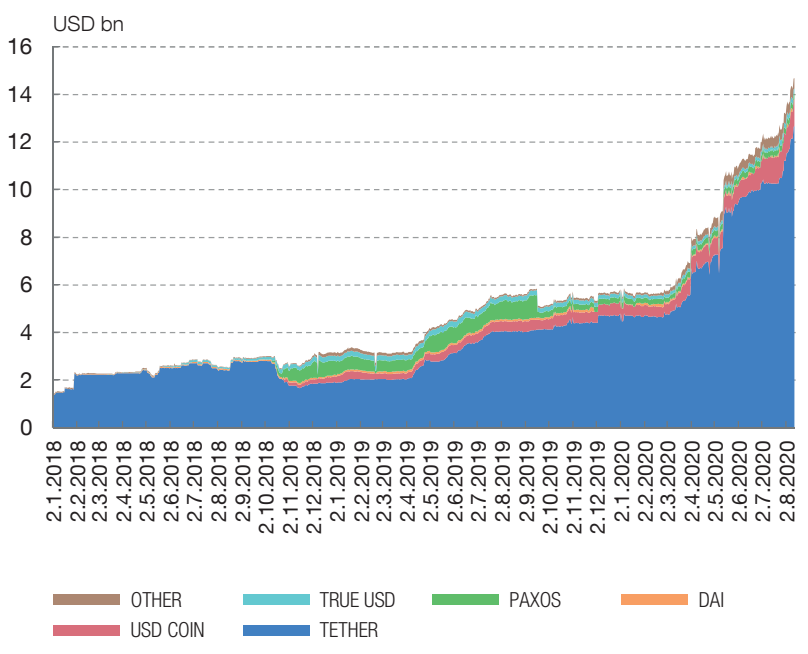

SOURCE: The Stablecoin Index, Messari.

a Histogram of daily trading prices in USD. The sample includes Tether (2 Jan 2018-14 Aug 2020), USD Coin (9 Oct 2018-14 Aug 2020), Dai (2 Jan 2018-14 Aug 2020), Paxos (28 Sep 2018-14 Aug 2020) and TrueUSD (6 Mar 2018-14 Aug 2020).

payment like credit cards and electronic wallets. In wholesale transactions, they could allow for "atomic settlement", i.e. delivery-versus-payment, where a payment and the transfer of ownership for e.g. a security happen at the same time.

To achieve these ambitions, stablecoins must have a stable value. For all stablecoins currently in existence, there has been some price volatility in practice, i.e. fluctuation relative to the reference assets (see Chart 2.1). This has led some policymakers to quip that stablecoins are neither stable nor coins [ECB (2019) and Woolard (2019)]. Nonetheless, volatility is much lower than that of Bitcoin, Ether and other cryptocurrencies. Over 2020, the market capitalisation of extant stablecoins (e.g. Tether, USD Coin, Dai and Paxos) has grown, from a low level (see Chart 2.2). The total market value of these coins reached USD 14 billion in August, dominated by Tether ${ }^{10}$. This is tiny relative to the global financial system and even relative to the market for crypto-assets, but this may understate their usage in specific contexts. Indeed, it is estimated that in mid-2018, up to $80 \%$ of Bitcoin trading volumes involved Tether on one side of the transaction [Vigna and Russolillo (2018)]. Moreover, it is notable that stablecoin market capitalisation has more than doubled since the start of the COVID-19 pandemic. In the same period, there has been a large rise in digital payments more generally, and in related services such as e-commerce [Auer et al. (2020c)].

10 This measure does not take into account JPM Coin, launched in February 2019 to enable instantaneous payments between institutional clients of JP Morgan based on blockchain [JP Morgan (2019)]. The current volume of JPM Coin is undisclosed. 


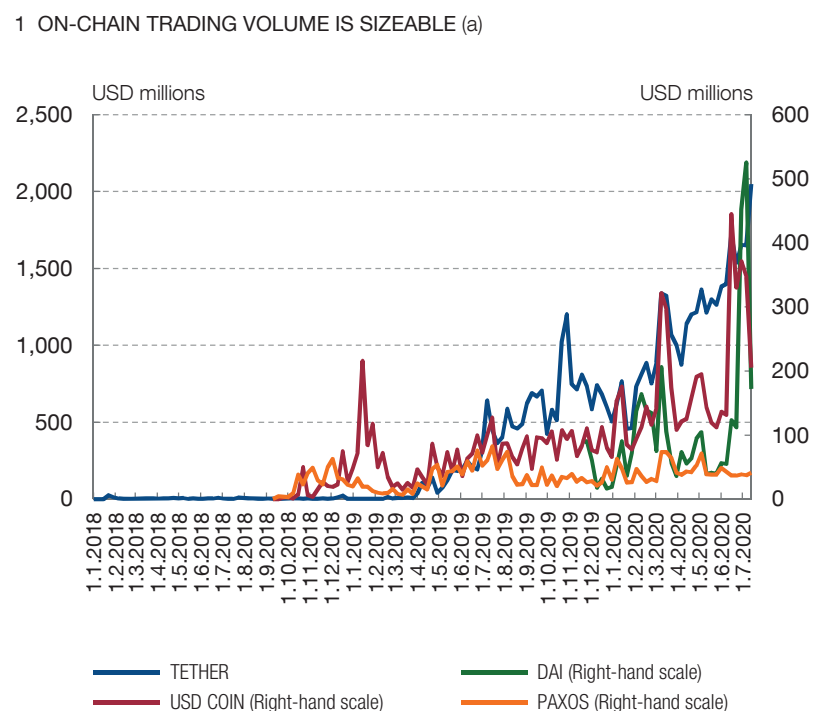

2 PLANNED COINS ARE NO LONGER SEEING SUBSTANTIAL ATTENTION (b)

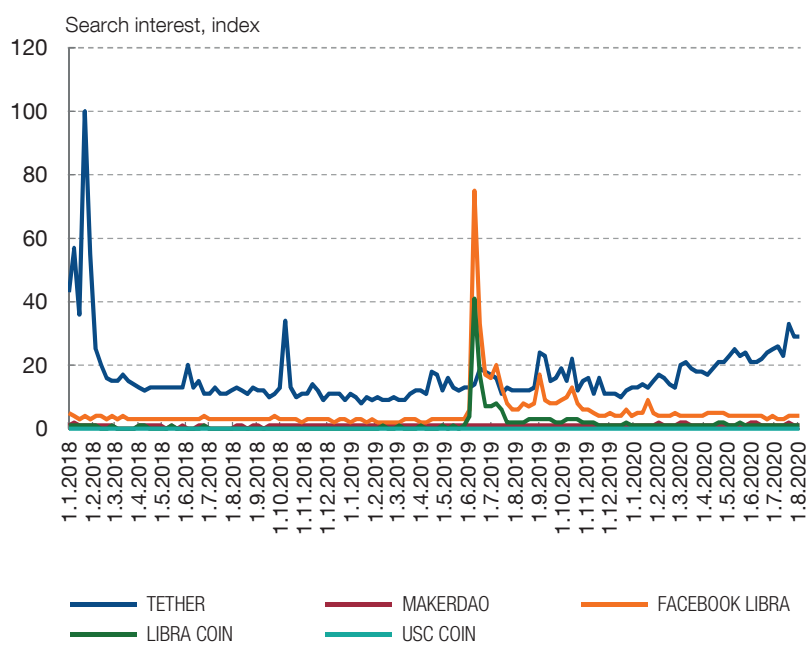

SOURCES: Glassnode Studio and Google Trends.

a Weekly average.

b Worldwide interest. Data accessed on 14 August 2020.

In parallel to the growth in market capitalisation (a stock measure), the use of stablecoins has increased, as seen in more transactions in stablecoins on the Bitcoin blockchain (a flow measure). In fact, total transfer volume in Tether reached USD 1.6 billion in July 2020, while on-chain transfers in Dai and USD Coin peaked at USD 400-500 million (see Chart 3.1). As a live coin, Tether continues to see high internet search interest from the general public, even as search interest in Facebook Libra has recently ebbed (see Chart 3.2).

These current trends are informative to the extent that they give clues into the potential future growth and operation of stablecoins. From what has been presented, at least three insights can be drawn. First, the value of stablecoins against reference assets may still fluctuate more than existing digital instruments like e-money. ${ }^{11}$ Second, while stablecoins are by nature less susceptible to speculative bubbles of the type that Bitcoin and other cryptocurrencies have experienced, their market capitalisation may nonetheless rise and fall rapidly with purchases and redemptions by investors. Worse yet, without additional private or public backstops, stablecoins can be subject to severe price discounts or selffulfilling runs, especially when backed by risky or opaque assets and in times of market turmoil. Furthermore, if stablecoins were to gain significant usage, runs on stablecoins could provoke fire sales of the assets used to back their value. This

11 Details of the pegging mechanisms differ across stablecoins. For example Lyons and Viswanath-Natraj (2020) argue that in case of Tether, it appears that most of the fluctuations are driven by arbitrageurs' inability to employ their balance sheets to profit from price differentials. 
could have negative spillovers on the rest of the financial system [Adachi et al. (2020) and G7 Working Group on Stablecoins (2019)]. Third, and more positively, indicators for monitoring stablecoins in real time are available. Prices, market capitalisation, on-chain transfers and search interest may all be useful measures of specific aspects of stablecoin markets. A forward-thinking design process may yield further indicators for the purpose of market monitoring and financial supervision that can be made available by design.

\section{Case study: the structure of Facebook's Libra 2.0}

While the potential attractiveness of stablecoins for specific use cases in DLT systems is clear, no cryptocurrency or stablecoin has emerged as a real competitor or alternative to major sovereign fiat currencies. From a regulatory standpoint, there have been clear regulatory and supervisory issues, in particular around market integrity [anti-money laundering/combating the financing of terrorism (AML/CFT)] and consumer and investor protection. So far, the concerns around financial or monetary stability have been limited in most jurisdictions.

\subsection{Libra 2.0: a primer}

This changed with Facebook's announcement in mid-2019 of its plan to create Libra, a combination of a private stablecoin and a global electronic payment framework. Facebook's initial proposal for the first "global stablecoin" ("Libra 1.0") met with considerable scepticism by policymakers around the globe. ${ }^{12}$ After an intense dialogue with regulatory authorities, on 16 April 2020, the Libra Association published a revamped "Libra 2.0" stablecoin proposal [Libra Association (2020)].

Libra 2.0 features a three-layer architecture. The first layer is the value backing of two distinct types of stablecoins: i) single-currency stablecoins in US dollars (USD), British pounds (GBP), euro (EUR) and Singapore dollars (SGD), referred to as Libra\$, Libra€, etc.; and ii) a global stablecoin (LBR) that is a basket of the single-currency stablecoins (see Chart 4). The second layer is the Libra Blockchain, the wholesale payment system where the Libra Blockchain makes stablecoins available to payment service providers (PSP) and e-wallet providers, such as Facebook's digital wallet Novi (previously called Calibra). In the third layer, the single-currency stablecoins and LBR are made available to other clients and wallets.

The value backing of the Libra stablecoin is two-tiered. The first tier is the Libra Reserve, a traditional asset-based value guarantee for single-currency stablecoins.

12 See Libra Association (2019) for the proposal, and G7 Working Group on Stablecoins (2019), FSB (2020) and Zetzsche et al. (2020b) for the policy discussion on Libra. 
Figure 1

THE ARCHITECTURE OF LIBRA 2.0: A GLOBAL LBR AND SINGLE-CURRENCY STABLECOINS

Libra 2.0 is to feature both single-currency stablecoins and a global stablecoin (LBR) that is a basket of the single-currency stablecoins. The architecture has three layers. The first layer is the value backing. In the second Libra Blockchain/wholesale layer, the various stablecoins are made available to retail payment providers through dealers/market makers. The third layer is that these payment service providers, in turn, make LBR and the single-currency stablecoins available to retail clients for use in payments.

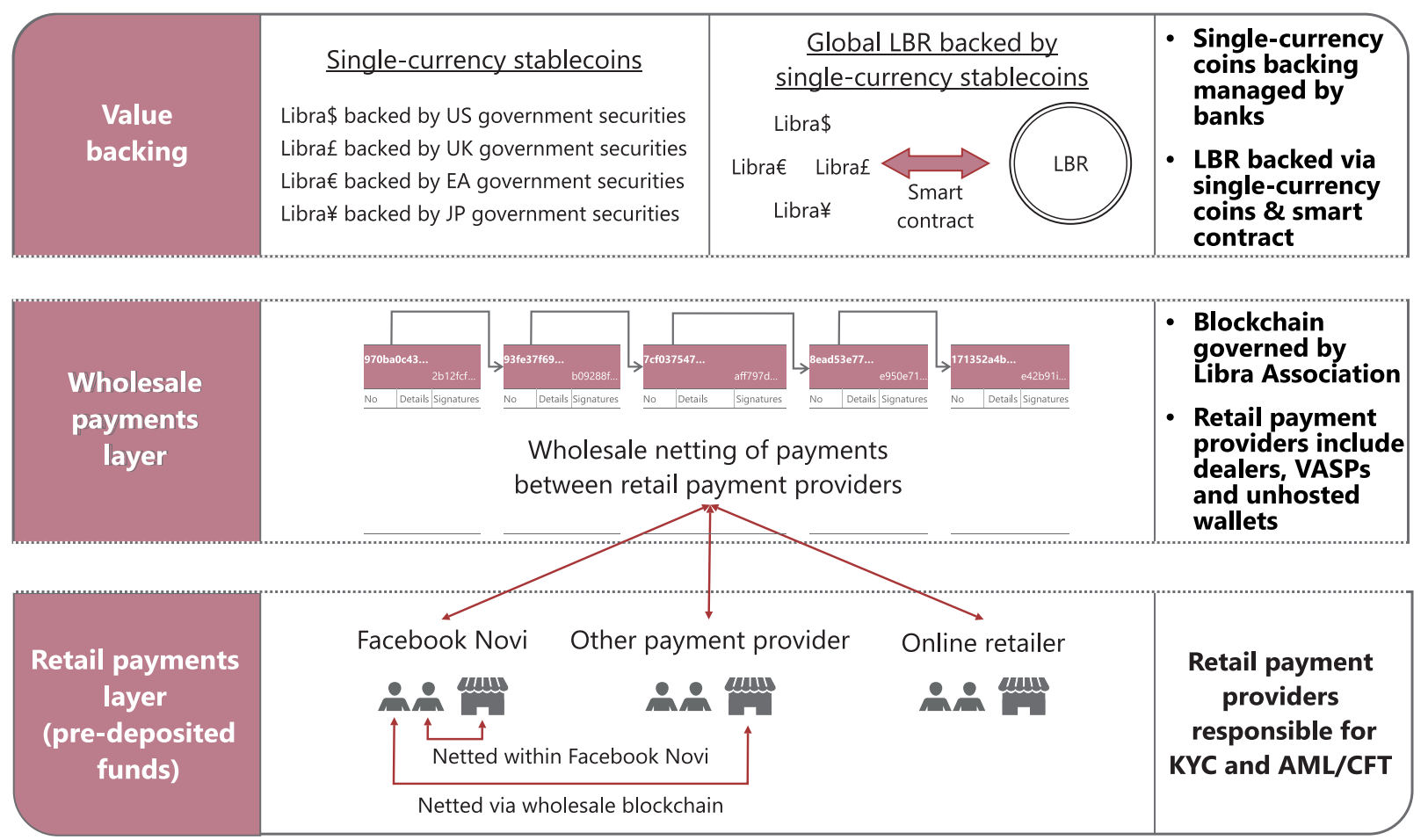

The second tier is a DLT-based smart contract combining single-currency stablecoins into the global stablecoin, LBR.

In the Libra Reserve, custodian banks hold assets on behalf of the Libra Association backing the single-currency stablecoins. The asset backing would be composed as follows. Over $80 \%$ are to be invested in short-term securities (up to 3 months remaining maturity) issued by liquid sovereigns with low credit risk (i.e. A+ rating from S\&P and A1 from Moody's, or higher). The remainder is to be held in cash, with overnight transfers into MMFs. The MMFs must invest in short-term liquid sovereign debt (up to 1 year remaining maturity) with low credit risk. The white paper notes that there will be no currency risk as the currency composition of assets will match the composition of outstanding single-currency stablecoins. The Libra reserve has provisions to address emergencies such as rapid outflows of funds during market turmoil. The Libra reserve can temporarily halt conversion or apply haircuts. 
The second tier of Libra 2.0 is a DLT-based global stablecoin. Custodian banks use their digital signature to cryptographically sign their guarantee into the public Libra Blockchain. Once these value guarantees are signed into the Libra Blockchain, LBR is a smart contract combining several single-currency stablecoins into a basket of currencies. For every LBR that is created, the smart contract "locks in" the respective amount of single-currency stablecoins on the Libra Blockchain. The white paper mentions as an example a 50\% weight for Libra\$, 18\% for Libra€, and $11 \%$ for Libra£ (the remaining $21 \%$ is not spelled out). ${ }^{13}$

All major policy decisions will require the consent of two-thirds of the Libra Association Council's representatives. Each of the association's members will have one council member, including Facebook, which will also have only one vote.

On the technological implementation of voting arrangements; the Association will not use permissionless DLT (i.e. abstain from using proof-of-work or proof-ofstake). ${ }^{14}$ This contrasts with the first white paper, which aimed to begin with a permissioned system then gradually move to permissionless DLT within 5 years. Instead, a permissioned DLT system will be used, similar to most major financial sector blockchain/DLT initiatives. The consensus protocol will require a two-thirds majority in line with the Association's voting rule.

The white paper has a comprehensive discussion on how to comply with AML/CFT regulation and due diligence. The Libra Association owns a subsidiary called Libra Networks, which is directly responsible for operating the Libra payment system, minting and burning Libra stablecoins and administering the Reserve. Members of the Association will become Validators of the network, i.e. they will validate the transactions on the Libra blockchain. It also specifies four different types of payment service participants:

- Designated Dealers (market makers buying and selling Libra stablecoins from/to Libra Networks and which do not interface directly with users).

- Regulated Virtual Asset Service Providers ("VASPs") that are registered or licensed as VASPs in Financial Action Task Force (FATF) member jurisdictions.

- Certified VASPs (certified by the Libra Association but not regulated by a public authority).

13 The white paper mentions the possibility that the basket weights are controlled "by a group of regulators and central banks or an international organization [e.g., IMF] under the guidance of the Libra Association's main supervisory authority [e.g., FINMA]".

14 See Budish (2018) and Auer (2019a) for an assessment of the economic potential of permissionless DLT. 
- "Unhosted wallets" - i.e. anonymous wallets which pose potentially high financial crime risks. (It is unclear if these wallets will meet regulatory requirements in practice).

VASPs and "unhosted wallet" providers would have the ability to offer consumer facing services, such as buying, selling, transferring and holding (in a wallet) Libra stablecoins. They will interface with Designated Dealers when required (e.g. to buy stablecoins against fiat currencies).

The white paper and a tweet by the Libra Association from 16 April 2020 state that the association has applied for a payment system license with the Swiss Financial Markets Authority (FINMA) for its subsidiary Libra Networks, confirmed by a press release from FINMA. ${ }^{15}$ The news agency Reuters reports that the Libra Association will register with the U.S. Treasury's Financial Crimes Enforcement Network (FinCen).

\subsection{Policy implications of Libra}

The description of the key issues in Libra Association (2020) is much clearer than the original white paper [Libra Association (2019)]. The Association has made progress in addressing some of central concerns voiced in G7 Working Group on Stablecoins (2019) and FSB (2020). In particular, it has addressed many of the AML/CFT concerns (aside from those generally existing around "unhosted wallets") and clearly detailed the backing of the reserve.

However, some key issues remain. Generally, it has been widely noted that Libra has been scaled down, but this is not necessarily true. Paramount is that LBR is to be created as a new unit of account with an elastic net supply, with potential for use in payments across the globe. One may argue that LBR is factually no different from the Libra 1.0 proposal. LBR is backed by a basket of country-specific stablecoins, which in turn are backed by high-quality sovereign assets. Libra 1.0 would have been backed directly by a basket of high-quality sovereign assets. The establishment of the individual major currency stablecoins does however largely address most concerns in those jurisdictions regarding currency substitution risks [Bank of Canada (2020)].

LBR does still threaten currency substitution, i.e. clients may use LBR as an alternative to the sovereign currency in a given jurisdiction, particularly those outside of major currency areas with established Libra stablecoins. This is noted in the new white paper: "If adoption in a region without a single-currency stablecoin on the network generates concerns about currency substitution, then the Association could work with

15 See https://twitter.com/Libra_/status/1250786192502685696. 
the relevant central bank and regulators to make a stablecoin available on the Libra network" [Libra Association (2020), p. 10].

That said, it is unclear how large demand for LBR will be, as many customers could prefer a single currency Libra (e.g. Libra\$). At the same time, for cross-border transactions in particular, the availability of not only LBR but also the single currency stablecoins may provide an attractive alternative for many markets with currencies that are not widely accepted outside of their jurisdiction.

It is also unclear how the single-currency stablecoins differ from other forms of financial intermediary-created money such as fractional reserve banking and money market funds. The white paper states that "because of the 1:1 backing of each coin, this approach would not result in new net money creation". However, if banks engaged in the equivalent activity of the single-currency stablecoins, that would be seen as money creation: the Libra Association will have government bonds as assets and sight-deposit like liabilities or functionally like a money market fund. The launch of the single-currency stablecoins could hence have systemic implications, and lead to a substantial part of the money supply being taken out of the control of the central bank and the banking system. It could also remove a significant stock of safe assets from the banking system, a concern voiced by Kahn et al. (2020).

The governance of the Association is also not fully elaborated. Voting among the members is spelled out, and a list of criteria for applying for membership is provided. The list touches on ownership and respectability of the company, AML/CFT compliance, the technical ability to run a validator node and more subjective aspects such as company location and the geographic reach of users. Periodic reviews of membership are planned. Yet it remains to be seen in practice if these fair and transparent rules will be adequately applied to all members, and therefore will allow for proper governance of the arrangement.

Compared with the 2020 FSB consultation report on "global stablecoin" (GSC) arrangements, which spells out 10 recommendations aimed at authorities and GSC arrangements, an early analysis of Libra 2.0 proposals reveals some gaps. In particular, the compliance framework described is geared towards AML/CFT and sanctions but does not inform on other aspects of market integrity, market conduct and consumer and investor protection. More generally, no details are given on a comprehensive compliance framework for the overall GSC arrangement and its service providers, including how to ensure ongoing compliance. No details are given regarding compliance with international standards from the Committee on Payments and Market Infrastructures (CPMI) and International Organization of Securities Commissions (IOSCO). These would be relevant for activities pertaining to a Libra as a systemically important payment system or other form of financial market infrastructure (FMI) and also to the management of the reserve [IOSCO (2020) and FSB (2020)]. 
Regarding AML/CFT compliance with FATF rules, certified VASPs and unhosted wallet providers will not benefit from the same level of compliance achieved by Regulated VASPs, and only the latter will seek full FATF compliance. Risk mitigation measures regarding the management of the reserve appear incomplete at this stage. For instance, details on loss-absorbing capital buffers, restrictions from lending and other aspects are missing, alongside further details on the composition of assets comprising the reserve. ${ }^{16}$

While the Libra Association plans contingency measures in response to stress scenarios that could result in a run from Libra stablecoins, contingency and business continuity plans are not provided for the overall GSC arrangement, e.g. in case of failure of a significant number of validators, and/or VASPs or unhosted wallets. No comprehensive resolution framework, including continuity and recovery of identified critical functions and activities of the Libra GSC arrangement is provided. No details are given on any contractual obligations in place to ensure such mechanisms are effective, or on the involvement of relevant authorities. This is a major omission.

\section{Principles for regulating stablecoins}

In order to address the concerns which have arisen around stablecoins and to provide an appropriate framework for market evolution, authorities around the world are working to develop regulatory systems and structures. At the international level, discussions around crypto-asset and stablecoin approaches are taking place through the G20, G7, FSB, IOSCO, BCBS, FATF and others. A range of other authorities including those in Switzerland, Russia and the UK have either enacted related legislation or are in the process of development. From the standpoint of major jurisdictions, probably the most comprehensive approach so far was announced by the EU in September 2020 [EC (2020)].

As a starting point, it is important to differentiate between stablecoins in general - which raise many regulatory issues but so far are not systemically important - and what the FSB has called "global stablecoins" or the EU calls "significant stablecoins" - where the bar for compliance on a range of policy issues will be much higher. In particular, the latter pose higher risks to financial stability, monetary policy transmission and monetary sovereignty that would not be present for more limitedpurpose coins. They may be considered "systemically important payment systems" or other forms of FMI. This section will consider principles for regulating both in turn.

In regulating any stablecoin, the starting point should be an appropriate registration or licensing regime, which allows for adequate information and monitoring, combined with prudential requirements in appropriate cases. It is essential to build systems to

16 Coelho et al. (2019) discuss how technology might help to bring down the cost of AML/CFT. 
collect data on such instruments. Thus, a registration requirement is likely to be useful in the jurisdiction of establishment. Because of the inherent cross-border potential, authorities will need to combine this with information sharing arrangements between each other. Without data and monitoring, potential financial stability risks may develop unobserved. In particular, there is the potential that a limited-purpose stablecoin may quickly evolve into a global stablecoin, thus fomenting much higher financial stability risks. This highlights the value of proportional graduated approaches, with differential treatment based on factors relating to the underlying structure or scale. For example, the proposed EU approach will provide different requirements for utility tokens (non-stablecoins), financial instruments (under the existing financial regulatory framework), e-money stablecoins (single currency, ondemand payment at par), asset-backed stablecoins, and significant stablecoins. The latter, which pass certain thresholds, have much higher regulatory requirements.

In addition to financial stability risks, stablecoins clearly raise a number of other regulatory and supervisory concerns, in particular in relation to market integrity and consumer/investor protection. ${ }^{17}$ Much attention has been already directed by international regulatory organisations - in particular the G20 and FATF - towards AML/CFT issues and approaches to crypto-assets and these apply fully to stablecoins. Likewise, international regulators - in particular IOSCO - are considering issues relating to market manipulation, fraud, abusive practices toward consumers, etc. [IOSCO (2020)]. These traditional market regulatory concerns arise in the stablecoin context as in the crypto-asset area more broadly. Yet stablecoin arrangements bring with them additional investor protection concerns given the link between the digital asset and fiat currency or other assets. In particular, stablecoin issuers may face a strong incentive to invest in risky assets, or to lend out assets backing the stablecoin, to achieve higher returns [see Frost et al. (2020)]. Indeed, in the absence of regulation, stablecoin issuers can earn a profit by investing in higherreturn or illiquid assets, or by lending funds or assets, while paying low or no interest to stablecoin holders. These incentives make asset segregation and collateral considerations key, in addition to market surveillance and disclosure frameworks. ${ }^{18}$

These arguments have historical and current examples. Throughout history, whenever new issuers have been successful in circulating a currency, they soon find themselves tempted to engage in profitable activities such as borrowing and lending. During the Mexican Revolution, for example, several different generals issued currencies or forced banks to make loans to pay soldiers' salaries, leading to high inflation and a debasement of the private bank currencies in circulation [Bátiz Vázquez (2009)]. As a more recent example, the issuer of Tether had until recently claimed that every Tether

17 Auer and Claessens (2018) build a database of regulatory news pertain to cryptocurrencies and examine how such events effect valuations and usage.

18 An additional facet is fraud. If a global stablecoin is able to enhance inclusion, it customers - who are less accustomed to managing their financial lives (especially online) - may be more vulnerable to phishing attacks and account takeovers in general. 

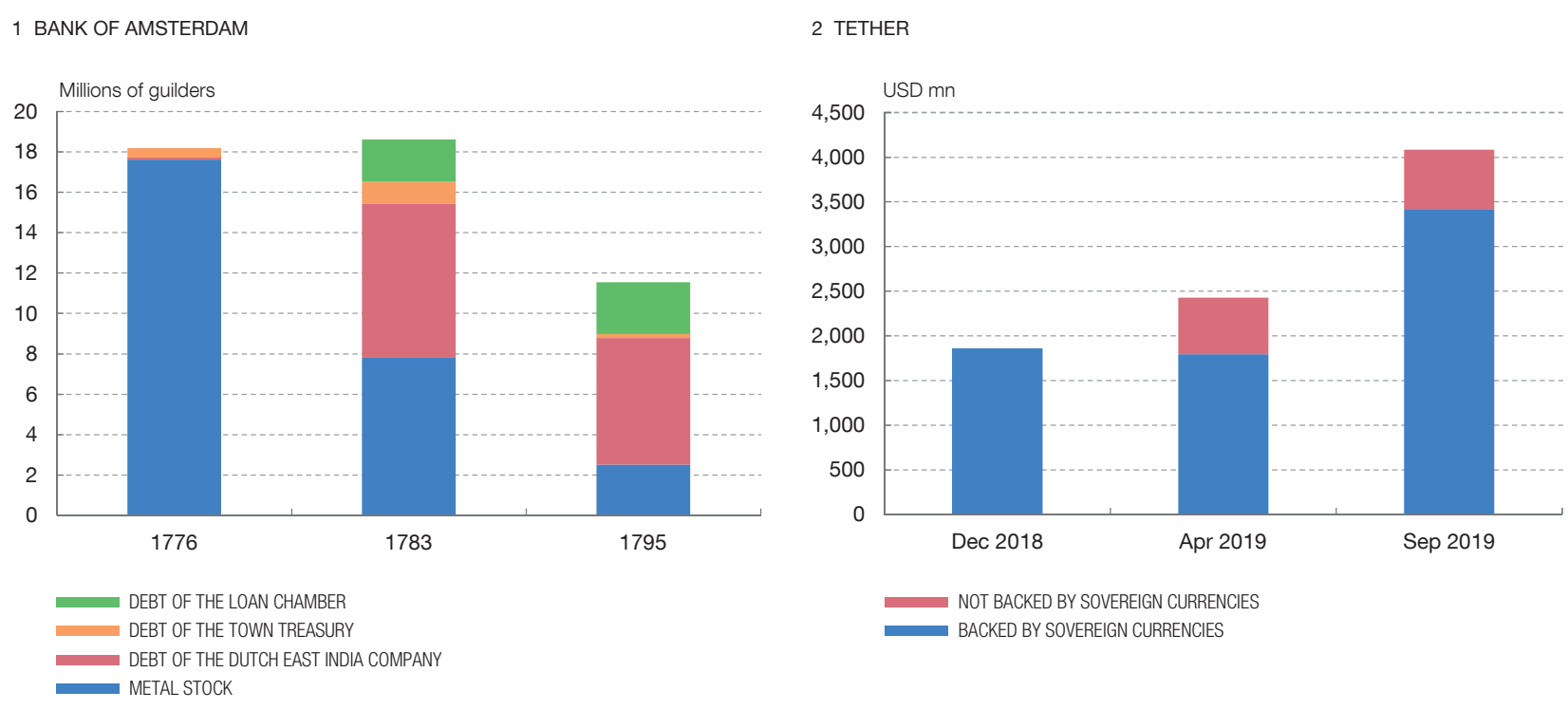

SOURCES: Van Dillen (1934), Frost et al. (2020), CoinMarketCap and author's calculations.

was $100 \%$ backed by fiat currency. Since 2019 , it has been accused by the New York Attorney General of lending at least $\$ 700$ million to Bitfinex, an affiliated crypto-asset trading platform [see NYAG (2019)]. The shift from full backing by safe assets to a mix of safe assets and credit is in some ways reminiscent of the Bank of Amsterdam in the late 18th century, which lent extensively to the Dutch East India company, the Town Treasury and Town Loan Chamber prior to its downfall. A key difference is that in Tether's case, the balances have actually continued to grow after the extent of lending to affiliated entities has come to light (see Chart 5). ${ }^{19}$

Regardless of their size, the digital and borderless nature of stablecoins will raise cross-border coordination issues. As such, as a first principle for policy, it will be essential to develop appropriate regulatory and supervisory tools in advance. This is particularly true from the standpoint of global stablecoins; tools should be activated when a global stablecoin or global stablecoin arrangement is identified. The tools could come from a variety of experiences. One example is the supervisory college approach which is now applied to large cross-border banks. Another comes from the experience with FMls: these are in some cases supervised via supervisory colleges, in others established under specific legal and regulatory systems as part of a cooperative design approach between private and public participants (such as SWIFT, CLS and

19 Griffin and Shams (2020) find, based on blockchain data, that purchases with Tether are timed following market downturns and result in sizable increases in Bitcoin prices. They argue that these results are "consistent with Tether being printed unbacked and pushed out onto the market" (p.1918). 
Euroclear). In some cases, this could involve regulation as a utility or operation by the central bank or otherwise itself [Zetzsche et al. (2021)]. Reflecting this approach, to the EU has proposed not only a framework addressing the full scope of digital assets, but also a separate framework for the licensing, regulation and supervision of DLT FMls.

Second, more informal means of cooperation will be needed. Memorandums of understanding (MoUs) and multilateral memorandums of understanding (MMoUs) could be helpful from a cross-border standpoint. The challenge in many cases will be the necessity to bring such instruments into the formal regulatory and supervisory perimeter of relevant authorities.

Third, beyond information sharing and enforcement, international standards may be particularly useful from the standpoint of approaches to embedded supervision - setting standards for the systems and approaches which could be required as part of the registration/licensing process for stablecoins. We return to this in the following section.

Fourth, for global stablecoins, specific regulatory treatment is necessary. Like most forms of systemically important FMI or financial institution - both domestic and global - systemic importance can be difficult to define precisely. ${ }^{20}$ The elements however are some combination of size, scale and interconnectedness: economies of scope and scale combined with network effects all potentially suggest systemic importance in the context of the financial system. This is reflected in the EU proposals, in the context of both "significant stablecoins" as well as DLT FMls.

In seeking an approach to global stablecoins, a key challenge is identification of GSCs. This is problematic because the entry of non-traditional participants in finance - particularly large technology companies (big techs) - means that existing size, scale etc. can all be leveraged very rapidly to achieve a dominant position in specific market segments or financial infrastructures [BIS (2019) and Petralia et al. (2019)]. From a financial stability standpoint, in addition to traditional risks of "too big to fail" and "too connected to fail", the private sector nature of stablecoins raises risks to monetary policy transmission and may threaten the effectiveness of the central bank's lender of last resort function. For all technological systems - private or otherwise - operational and cyber incidents are relevant, but these become even more pressing for a stablecoin that may be very widely adopted. Because of the scale, other issues also rise to the financial stability level, including market integrity (the risk of a global stablecoin being widely used for criminal activities), consumer protection (the risk that a collapse destroys many individuals' financial resources) and risks of anti-competitive behaviour and restrictions on innovation (due to market dominance). Such identification could build on frameworks for global systemically important financial institutions (G-SIFIs), or could be done in the context of a specific proposal - as in the context of Libra, or as has been done with CLS. Proposals could be

20 For a discussion of indicators on systemic importance in the context of banking, see BCBS (2013). 
both purely private or some sort of public-private process, as has been historically more common in the evolution of major payments infrastructure domestically, regionally and internationally.

The content of the regulatory approach would involve a variety of specific instruments. These could be activity-based, entity-based or infrastructure-based depending on the nature of the specific GSC. Activity-based approaches would vary depending on the nature of the products and services offered. These could relate to payments, securities, etc. Cooperation and coordination on licensing, market access, supervision, resolution, etc. would all be required.

The key point is that the Libra experience should be used as an opportunity to develop systems at the global level to identify GSCs, to put in place appropriate supervisory arrangements and to monitor their activities and impact. This is exactly the approach that is being pursued in the context of the development of a set of 10 principles from the FSB to address GSCs [FSB (2020)] as well as the new EU proposals. The FSB principles highlight:

- the need of the supervisory authority to have appropriate powers, tools and resources;

- that regulatory requirements should be applied on a functional and proportional basis;

- that there is comprehensive regulation, supervision and oversight on a cross-border basis and that these are met by a GSC arrangement before commencing operations;

- that GSC arrangements have in place a comprehensive governance, risk management and fit and proper framework, robust data systems, appropriate resolution and recovery plans; and

- that GSC arrangements provide sufficient data and legal clarity for users, particularly around redemption and insolvency.

In looking at approaches, to the extent that one is creating an automated financial product, it may well make sense to explore automated or embedded supervisory approaches (see next section).

Last, the repercussions of stablecoins on the disintermediation of the traditional banking sector should also be taken into account. If consumers switch from sight deposits and payment accounts towards stablecoins, traditional bank lending could become costlier [see Kahn (2016)]. A closely related implication is that certain central banks could receive substantial inflows onto their balance sheets if stablecoins are 
to be restricted to keep reserves at the central bank (as is often the case under e-money regulations). This may also affect the transmission of monetary policy.

\section{From regulation to supervision: the promise of "embedded supervision"}

Regulation and supervision are evolving with technology. In some cases, in addition to the use of technology for regulatory compliance, monitoring and implementation (regtech and suptech), regulatory and supervisory requirements are being built into technological systems. Some jurisdictions are already implementing or planning automated reporting [see EC (2020)]. In recent work, Auer (2019b) puts forward the concept of "embedded supervision". Embedded supervision is a framework that provides for compliance to be automatically monitored by reading the ledger of a DLT-based market (see Chart 6). The ledger of a DLT-based market contains much information relevant for supervisory purposes. As such, it can be used to improve the quality of data available to the supervisor, while reducing the need for firms to actively collect, verify and report data to authorities. Through their use of DLT, stablecoins could allow this approach in practice.

Allowing for embedded supervision could be of substantial importance for the development of so-called asset "tokenisation" - the process by which claims on or ownership in real and financial assets are digitally represented by tokens, allowing for new forms of trading and improved settlements [Bech et al. (2020)]. In particular, one key early use case of embedded supervision may be in the monitoring of the full asset backing of a blockchain-based stablecoin. Currently, USDC and Paxos publish monthly public auditor reports of the smart contract and of the reserve on their websites; to reduce fraud risk this process could be fully automated and even realtime. ${ }^{21}$ To exemplify both the merits and limits of embedded supervision applied to stablecoins, consider the revised Libra proposal. ${ }^{22}$ Libra 2.0 highlights that when it comes to applying embedded supervision, one needs to carefully distinguish the use of DLT from other traditional elements that involve technology, but still rely on the value underpinning provided by supervised institutions and the legal system. Auer (2019b) discusses principles that should govern a framework designed to make use of a market's distributed ledger for financial supervision.

A first of these principles goes back to how the value underpinning of the singlecurrency stablecoins is guaranteed in Libra 2.0: it is the banks' digital signatures in the ledger that underpin the value of these coins. Obviously, there is nothing other than the judicial system that obliges banks to honour these guarantees. The first principle of embedded supervision is that the process of tokenisation must be supported by the

21 There are many concerns with Libra that go beyond the discussion of the value backing discussed, see the above discussion in Section 4.

22 Other examples include MakerDao's DAI, as well as other "on-chain" stablecoins in the terminology of Bullmann et al. (2019). 
Embedded supervision can verify compliance with regulations by reading the distributed ledgers in both wholesale (symbolised by the green blockchain) and retail banking markets (symbolised by the yellow blockchain). Supervisors could access all transaction-level data. Alternatively, the use of smart contracts, Merkle trees, homomorphic encryption and other cryptographic tools might give supervisors verifiable access just to selected parts of such micro data, or relevant consolidated positions such as to institution-to-institution or sectoral exposures. Firms would only need to define the relevant access rights, obviating the need for them to collect, compile and report data.
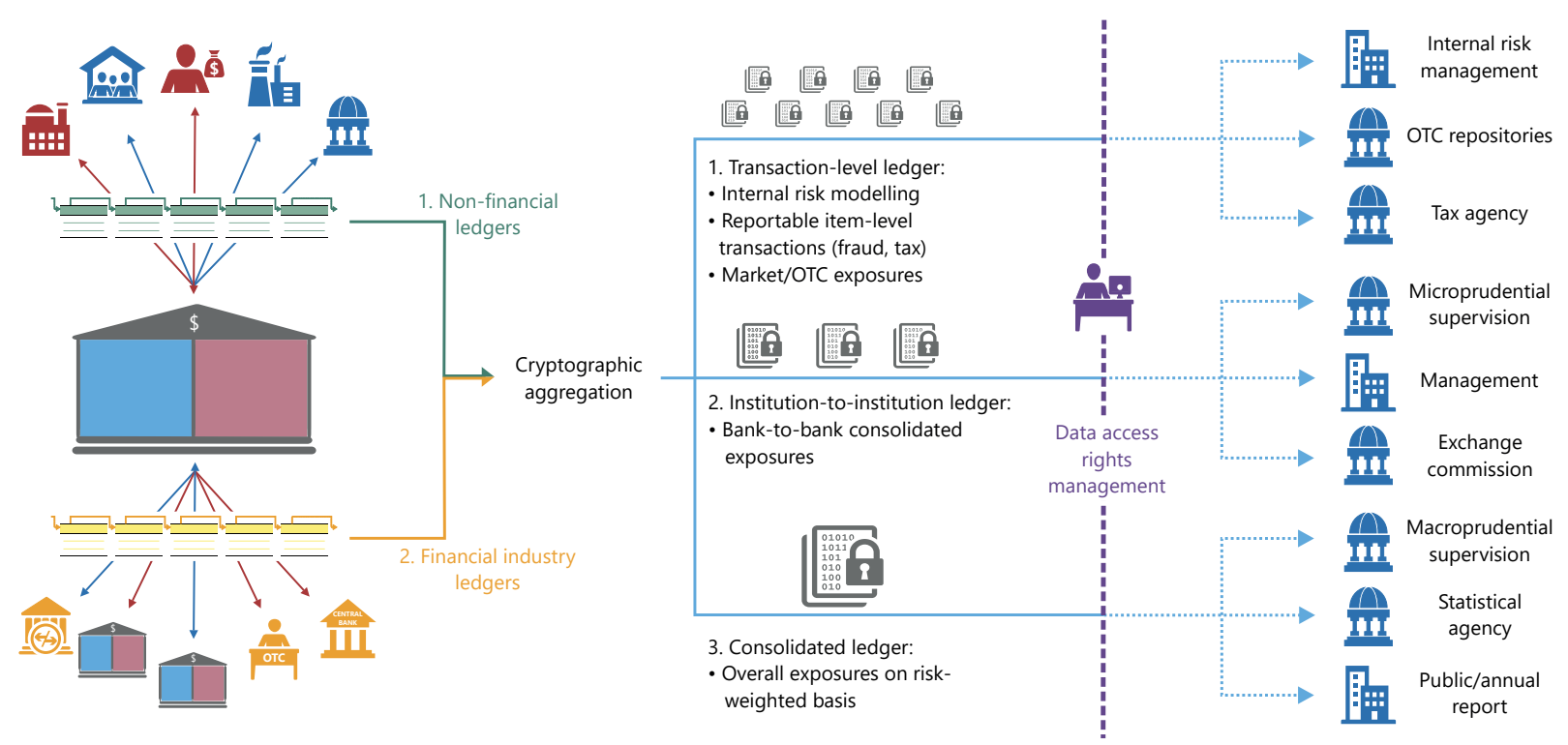

SOURCE: Auer (2019b).

legal system. The connection between the claim on or ownership in the underlying asset and the record of the digital token must ultimately be established by the legal system and relevant contractual arrangements. This is true for stablecoins, but also for assets such as real estate or shares in a bricks-and-mortar business. Importantly, this means that just as in a traditional financial system, a decentralised financial system needs to be backed up by an effective legal and judicial system and supporting enforcing institutions for contractual arrangements [see Zetzsche et al. (2020a)].

A second principle relates to exchange in DLT-based markets: transactions and transfer of ownership must be irrevocable and final - otherwise balance sheet items are not definitive [see CPMI-IOSCO (2012) and CPMI (2017)]. Even with "permissioned" DLT, there may be no central entity capable of vouching for finality with a legally binding signature. The risks of one party failing to settle transactions remain [Bech et al. (2020)]. As such, another criterion for transaction finality must be established, with payment finality being a particular concern.

A third principle is to consider how the market will react to being automatically supervised. Embedded supervision focuses on the concept of economic finality 
proposed in Auer (2019a), i.e. economic finality is the notion that a transaction is final once it is no longer profitable to reverse it. ${ }^{23}$ When it comes to applying this consideration to the case of Libra 2.0, the white paper does not spell out how transaction finality will be achieved. It does spell out a standard process to achieve consensus on transactions via a $2 / 3$ supermajority among the association members. What is however missing is a set of rules that would spell out what were to happen if indeed $2 / 3$ of the members of the association were to coordinate to fraudulently undo transactions via so-called history reversion attack. Further information is thus needed to establish economic finality, and to ensure that attempts to deceive the supervisor will be unprofitable. ${ }^{24}$ It is of course important to remember that technological finality or even contractual finality is not the same as legal payment finality [see Zetzsche et al. (2018)], which will generally require settlement across the books of the central bank or via an appropriately authorised payment system.

The last principle concerns the broader societal goals when designing embedded supervision. Despite substantial technological advances of recent decades, financial services have for a long time remained expensive [Philippon (2015) and Bazot (2018)]. This might partly reflect high barriers to entry in financial services, some of which are created by the administrative burden of complying with financial regulation. As a side effect of their focus on detailed regulation and supervision to tackle the risks of large and complex financial intermediaries, supervisors may have inadvertently further favoured concentration - by creating compliance costs that weigh disproportionately on smaller intermediaries (see Chart 7). ${ }^{25}$ While these are certainly not the only barriers to entry in financial markets, measures to reduce such costs may enhance competition and contestability.

One goal of embedded supervision should hence be to achieve high-quality compliance at lower cost, thus levelling the playing field for large and small institutions. ${ }^{26}$ In the context of Libra 2.0, one operational aspect is for supervisors to take an active role in the design of the market, in particular regarding standardisation of the database structure - for example, to ensure interoperability of the Libra blockchain with other blockchains. A second goal might be to develop a freely available open-source suite of monitoring tools with the aim of clarifying how specific regulatory frameworks are applied in practice. A third goal is to ensure the legal finality of payments, as is the case for today's payment systems.

23 Auer (2019a) examines economic finality for the proof-of-work-based consensus schemes used in Bitcoin.

24 Auer (2019b) extends the theoretical considerations regarding transaction finality to the impact of the supervisors' actions on the regulated market. Regulated firms incur a cost in complying with regulation that they would not incur voluntarily. By the same token, in the DLT world, this creates incentives for a regulated firm to cheat the supervisor by altering the transaction history in the blockchain. He thus also models the supervisor's impact on the market.

25 In particular, following the Great Financial Crisis, politicians, legislators and supervisors have focused on increasing the resilience of the financial system and, in particular, of the large banks that account for the bulk of total positions and thus aggregate risk, an effort that is still ongoing [see e.g. Carstens (2018)].

26 See Broeders and Prenio (2018) for a general assessment of suptech in bringing down the cost of compliance. 


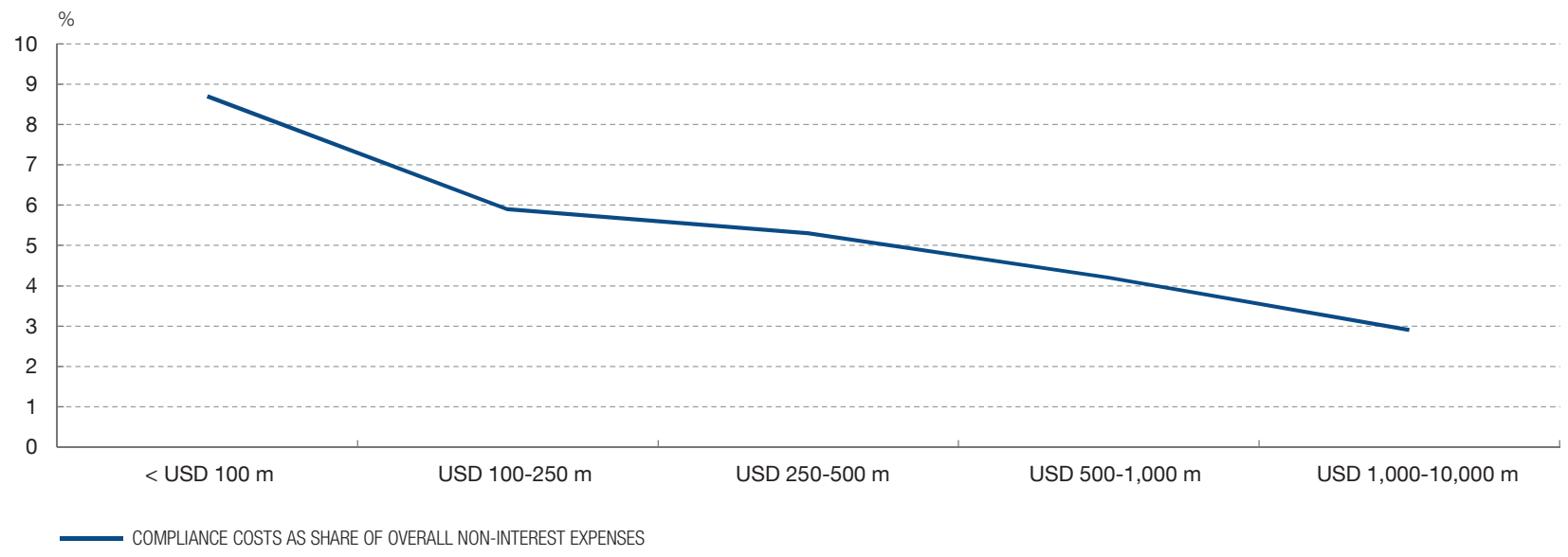

Efficient guidance of market standards to ensure contestability may also require an adequate definition of what it means to truly "decentralise" decision-making, risktaking and system governance [see Buterin (2017) and FSB (2019) for a discussion, and Walch (2019) for a critical review]. ${ }^{27}$ Regulators and supervisors can steer some design elements of new decentralised markets, as they will set the market standards under which regulatory compliance can be automated [see also Zetzsche et al. 2020a)].

A further operational goal is to reduce the marginal cost of doing business by facilitating access to trustworthy official information. One measure that could be easily implemented would be for public authorities to directly offer digitally signed and time-stamped information that could be fed into relevant market ledgers - or to set standards so that private intermediaries could do so. In many cases, financial contracts may reference data originating from the official sector, such as the central bank's policy rate or data releases from the national statistical office. Moreover, in many jurisdictions, firm and land registries are operated by the government. Low-cost tokenisation of the underlying firms and real estate would be facilitated if these registries were to make their information accessible in a digitally signed, time-stamped and publicly available form.

A last operational aspect concerns the handling of disputes. Regulatory frameworks or standards could guide arbitration processes if any information referenced in smart

27 Even with the most decentralised systems, many aspects of centralisation remain, for example when it comes to the evolution of the code (core developers, etc.). Further to this, as shown by the concentration of the mining power of all of the world's major cryptocurrencies in the hands of only a few companies or mining pools, even systems that are intended to be decentralised have a tendency to centralise, owing to unforeseen returns to scale. Regulators and supervisors could counter this, for example, by setting standards that guide or encourage entry into the verification market or by mandating open data requirements. 
contracts turns out to be fraudulent. This could happen where the smart contract has a security flaw (as is frequently the case) [see Luu et al. (2016) and Fröwis and Böhme (2017)] or in other unforeseen events, such as if a smart contract depends on an interest rate benchmark that ceases to exist. Ultimately, though, the world is sometimes too complex to be put into code. Moreover, cases concerning individuals may generate personal information that needs to be handled with confidentiality, and such that users have recourse if data are used improperly. Thus, the more intractable cases may always need to be handled via an old-fashioned legal process [see Zetzsche et al. (2018)]. In this light, the added value of decentralised automation should be seen as simplifying the standard execution of a contract.

One possible function of stablecoins - a desired function from the standpoint of users - is to provide a digital means of payment which can be embedded in both DLT and traditional centralised environments in order to reduce payment and settlement risks and transaction costs, in particular enhancing user trust in systems and payments. One could think of this as "embedding" payments within transactions and their settlement. From this standpoint, stablecoins offer a potentially desirable innovation but also one which could create a range of new risks and concerns.

However, this discussion highlights that a better solution could in fact be using technology to embed fiat currencies in the same way, for instance in the context of central bank digital currencies (CBDCs). Central banks around the world are researching and developing CBDCs [Boar et al. (2020) and Auer et al. (2020b)]. Both wholesale and retail CBDCs provide a combination of private sector expertise and central bank value backing and infrastructure. By design, CBDCs would have a fixed value against other representations of the central bank's currency. Indeed, in most designs, a CBDC would be a direct claim on the central bank in question [Auer et al. (2020b)]. While private sector intermediaries still may offer client-facing services, the inherent conflicts of interest, by which intermediaries seek to achieve higher returns with the funds entrusted to them, would be eliminated. Even "synthetic" CBDC arrangements in which a stablecoin is not a claim on the central bank, but in which the issuer has direct access to central bank liquidity, similar to many RTGS systems, could offer some of these benefits.

Some of the benefits also could be achieved through less far-reaching reforms to existing payment systems. For instance, retail fast payment systems (FPS) may allow for the 24/7 availability and speed that consumers and businesses are demanding. It may also be possible to programme payments in such a way as to support atomic settlement (immediate "delivery-vs-payment"), to allow for very small values (micropayments) or to be interoperable with DLT systems. Together with advances in digital ID, such systems could also work to enhance financial inclusion and universal access [Arner et al. (2018)]. Indeed, the recent experience with the India Stack [D'Silva et al. (2019)] shows that great strides can be achieved through public payment and other infrastructures that do not rely on DLT, stablecoins or CBDCs. Unlike CBDCs, FPS 
build on existing accounts at intermediaries. Such accounts are not backed by the sovereign, but they also do not lead to concerns around "digital runs" or disintermediation. It is possible for such advances to be complementary to efforts to issue a CBDC as a robust public digital means of payment.

From the standpoint of payment finality, this typically is defined to occur when a transfer takes place in the books of the central bank. Finality can also take place if the relevant legal framework provides for it to take place in the context of a regulated payment system. As such, while a stablecoin or FPS may not offer finality in the same way as a CBDC (as CBDC payments would settle across the books of the central bank, both in token-based or account-based systems), the legal and regulatory framework for the licensing and supervision of payments systems must provide for requirements for systems to provide for such finality. This would provide a clear opportunity for mandating embedded supervision into such systems. ${ }^{28}$

Overall, it is not clear that stablecoins are necessarily needed to provide some of the benefits that they purport to serve. While a digital representation of value could hold great potential in many applications, CBDCs may offer these benefits without the inherent fluctuation in value or conflicts of interest entailed by stablecoins. Improvements to existing payment infrastructures, or new infrastructures that do not rely on DLT, may also be able to fulfil many of the use cases for stablecoins. FPS may serve some of the same goals, or serve as a useful complement. Thus, in the same way that stablecoins from previous centuries [Frost et al. (2020)] were an evolutionary step on the road to central banking, today's stablecoins could too eventually give way to other reforms. This may include robust sovereign-backed alternatives and new means to connect central bank money across borders [Auer et al. (2020d)].

\section{Conclusion}

Finance and technology continue to evolve together. Today, technology is not only transforming finance, but money as well, with the advent of a range of challengers to traditional sovereign currencies, from Bitcoin to Libra. Of these, the evolution of new technology-based "stablecoins" offers important potential to embed a digital monetary instrument in distributed systems and transaction frameworks. Yet as with all technologies for payments and all structures involving asset backing, there is a need for adequate regulation. Moreover, while most stablecoins offer limited financial and monetary stability risk, the advent of global stablecoins raises much larger issues and concerns. Going forward, it is essential for authorities have the tools, skills and technology to identify the evolution or creation of stablecoins, in

28 International spillovers have to be take into account in the context of CBDC design. Ferrari et al. (2020) show that CBDC issuance amplifies international spillovers of macroeconomic shocks. However, the magnitude of these effects depends on CBDC design features; for example they can be mitigated by limits on transactions by nonresidents. 
particular global stablecoins, and to build appropriate regulatory and supervisory frameworks.

Technology also offers the potential not only to enhance supervision but in fact to provide new tools for implementing regulation. Stablecoins and other forms of decentralised finance not only provide regulatory and supervisory challenges but also opportunities for embedding supervisory and monitoring frameworks directly into systems during the process of their creation and authorisation. This has the potential to enhance achievement of regulatory and supervisory objectives through the technology which initially was targeted with making the role of regulation unnecessary. Still, there are open questions as to whether central bank infrastructures, like CBDCs or retail fast payment systems, with a role for private sector services built on top, could provide many of these same opportunities more effectively. 


\section{REFERENCES}

Adachi, M., M. Cominetta, C. Kaufmann and A. van der Kraaij (2020). "A regulatory and financial stability perspective on global stablecoins", Macroprudential Bulletin, No. 10, Frankfurt am Main, ECB, March.

Arner, D., J. Barberis and R. Buckley (2017). "FinTech, RegTech and the Reconceptualization of Financial Regulation”, Northwestern Journal of International Law and Business, Vol. 37, No. 3.

Arner, D., R. Buckley and D. Zetzsche (2018). FinTech for Financial Inclusion: A Framework for Digital Financial Transformation, AFI Special Report, Group of Twenty Four.

Arner, D., R. Buckley, D. Zetzsche and A. Didenko (2020). After Libra, the Digital Yuan and COVID-19: Central Bank Digital Currencies and the New World of Money and Payment Systems, European Banking Institute Working Paper, No. 65, July.

Auer, R. (2019a). Beyond the doomsday economics of "proof-of-work" in cryptocurrencies, BIS Working Papers, No. 765, January.

- (2019b). Embedded supervision: how to build regulation into blockchain finance, BIS Working Papers, No. 811.

Auer, R., and R. Böhme (2020). "The technology of retail central bank digital currency”, BIS Quarterly Review, March, pp. 85-100.

Auer, R., and S. Claessens (2018). "Regulating cryptocurrencies: assessing market reactions", BIS Quarterly Review, September.

Auer, R., G. Cornelli and J. Frost (2020a). "Covid-19, cash and the future of payments", BIS Bulletin, No. 3, April.

- (2020b). Rise of the central bank digital currencies: drivers, approaches and technologies, BIS Working Papers, No. 880, August.

Auer, R., J. Frost, T. Lammer, T. Rice and A. Wadsworth (2020c). Inclusive payments for the post-pandemic world, SUERF Policy Note, August.

Auer, R, P. Haehne and H. Holden (2020d). Multi-CBDC arrangements and the future of cross-border payments, BIS Papers, forthcoming.

Bank of Canada (2020). Contingency planning for a central bank digital currency, February.

Bátiz Vázquez, J. (2009). "Paper money in the Mexican revolution", in F. Rubli (ed.), Money in the Mexican War of Independence and Revolution, Mexico City, Bank of Mexico.

Bazot, G. (2018). Financial intermediation cost, rents, and productivity: An international comparison, Working Papers, No. 0141, European Historical Economics Society (EHES).

BCBS (2013). Global systemically important banks: updated assessment methodology and the higher loss absorbency requirement, 3 July.

Bech, M., and R. Garratt (2017). "Central bank cryptocurrencies”, B/S Quarterly Review, September, pp. 55-70.

Bech, M., J. Hancock, T. Rice and A. Wadsworth (2020). "On the future of securities settlement", BIS Quarterly Review, March, pp. 67-83.

BIS (2018). "Cryptocurrencies: looking beyond the hype", Annual Economic Report, Chapter 5, June.

- (2019). "Big tech in finance: opportunities and risks", Annual Economic Report, Chapter 3, June.

- (2020). "Central banks and payments in the digital era", Annual Economic Report, Chapter 3, June.

Boar, C., H. Holden and A. Wadsworth (2020). Impending arrival - a sequel to the survey on central bank digital currency, BIS Papers, No. 107, January.

Broeders, D., and J. Prenio (2018). Innovative technology in financial supervision (suptech) - the experience of early users, FSI Insight, No. 9, July.

Budish, E. (2018). The Economic Limits of Bitcoin and the Blockchain, University of Chicago Booth School of Business Working Paper.

Bullmann, D., J. Klemm and A. Pinna (2019). In search for stability in crypto-assets: are stablecoins the solution?, Occasional Paper Series, No. 230, ECB, August.

Buterin, V. (2017). "The meaning of decentralization”, Medium.com, 6 February. 
Carstens, A. (2018). "Sustaining the momentum", speech, 24 June.

- (2019). "The future of money and the payment system: what role for central banks?", speech, 5 December.

Coelho, R., M. de Simoni and J. Prenio (2019). Suptech applications for anti-money laundering, FSI Insights, No. 18.

CPMI (2017). Distributed ledger technology in payment, clearing and settlement - an analytical framework, February.

CPMI-IOSCO (2012). Principles for Financial Market Infrastructures, April.

Dahl, D., A. Meyer and M. Neely (2016). "Scale matters: community banks and compliance costs", The Regional Economist, July, Federal Reserve Bank of St. Louis.

D’Silva, D., Z. Filková, F. Packer and S. Tiwari (2019). The design of digital financial infrastructure: lessons from India, BIS Papers, No. 106.

EC (2020). Proposal for a regulation of the European Parliament and of the Council on Markets in Crypto-assets, and amending Directive (EU) 2019/1937, September.

ECB (2020). "Stablecoins - no coins, but are they stable?", IN FOCUS, No. 3.

Fatás, A., and B. Weder di Mauro (2019). "The benefits of a global digital currency”, VoxEU.org, 30 August.

Feltwell, T., C. Elsden, S. Lawson and J. Vines (2019). “Recipes for Programmable Money”, Proceedings of the 2019 CHI Conference on Human Factors in Computing Systems.

Ferrari, M., A. Mehl and L. Stracca (2020). Central bank digital currency in an open economy, CEPR Discussion Paper, No. 15335.

Fisher, I. (1933). “The Debt Deflation Theory of Great Depressions”, Econometrica, Vol. 1, pp. 337-357.

Frost, J., H. S. Shin and P. Wierts (2020). An early stablecoin? The Bank of Amsterdam and the governance of money, BIS Working Papers, No. 902.

Fröwis, M., and R. Böhme (2017). "In code we trust? Measuring the control flow immutability of all smart contracts deployed on Ethereum", in J. García-Alfaro, G. Navarro-Arribas, H. Hartenstein and J. Herrera-Joancomartí (eds.), Data privacy management, cryptocurrencies and blockchain technology, Springer, pp. 357-372.

FSB (2017). Financial stability implications from fintech: supervisory and regulatory issues that merit authorities' attention, June.

- (2019). Decentralised financial technologies: Report on financial stability, regulatory and governance implications, June.

- (2020). Addressing the regulatory, supervisory and oversight challenges raised by "global stablecoin" arrangements, 14 April.

G7 Working Group on Stablecoins (2019). Investigating the impact of global stablecoins, October.

Gartner (2020). Gartner Glossary, available online at https://www.gartner.com/en/glossary, accessed 15 August.

Griffin, J., and A. Shams (2020). "Is Bitcoin Really Untethered?", The Journal of Finance, Vol. 75, No. 4, pp. 1913-1964.

IOSCO (2020). Global Stablecoin Initiatives, March.

JP Morgan (2019). JP Morgan Creates Digital Coin for Payments, February.

Kahn, C. (2016). "How are payment accounts special?", Payments Innovation Symposium, Federal Reserve Bank of Chicago.

Kahn, C., C. Long and M. Singh (2020). Privacy Provision, Payment Latency, and Role of Collateral, IMF Working Paper WP/20/148.

Kane, E. (1977). "Good Intentions and Unintended Evil: The Case Against Selective Credit Allocation", Journal of Money, Credit and Banking, No. 9, pp. 55-69.

- (1981). "Accelerating Inflation, Technological Innovation and the Decreasing Effectiveness of Banking Regulation", Journal of Finance, No. 36, pp. 355-367.

Kindleberger, C. P. (1978). Manias, Panics and Crashes: A History of Financial Crises, New York, Basic Books.

Knot, K. (2019). "Risks and benefits of modern financial technology; Lessons from a 17th century stablecoin", speech, 2 December. Libra Association (2019). An Introduction to Libra, 18 June.

- (2020). White Paper: v2.0, Libra Association Members, 16 April. 
Luu, L., D. Chu, H. Olickel, P. Saxena and A. Hobor (2016). "Making smart contracts smarter", in Proceedings of the 2016 ACM SIGSAC Conference on Computer and Communications Security, pp 254-269.

Lyons, R., and G. Viswanath-Natraj (2020). What Keeps Stablecoins Stable?, National Bureau of Economic Research WP, No. w27136.

McLaughlin, T. (2020). Two Paths to Tomorrow's Money, Citi Digital Policy, Strategy and Advisory Paper.

Milkau, U. (2018). "The advent of machine payments: The right way to pay?”, Journal of Payments Strategy \& Systems, Vol. 12 , No. 4.

Minsky, H. (1975). John Maynard Keynes, New York, Columbia University Press.

- (1982). The Financial-Instability Hypothesis: Capitalist Processes and the Behavior of the Economy, Hyman P. Minsky Archive, Paper 282.

NYAG (2019). "Attorney General James Announces Court Order Against 'Crypto' Currency Company Under Investigation For Fraud”, Press release, 24 April.

Petralia, K., T. Philippon, T. Rice and N. Véron (2019). Banking Disrupted? Financial Intermediation in an Era of Transformational Technology, Geneva Report, No. 22, September.

Philippon, T. (2015). "Has the US Finance Industry Become Less Efficient? On the Theory and Measurement of Financial Intermediation", American Economic Review, Vol. 105, No. 4, pp. 1408-1438.

Tether (2016). Tether: Fiat currencies on the Bitcoin blockchain, tether.to.

Van Dillen, J. (1934). "The Bank of Amsterdam”, in J. G. van Dillen (ed.), History of the Principal Public Banks, The Hague, Martinus Nijhoff, pp. 79-124.

Vigna, P., and S. Russolillo (2018). "The Mystery Behind Tether, the Crypto World's Digital Dollar”, The Wall Street Journal, No. 12 August.

Wadsworth, A. (2018). "Decrypting the role of distributed ledger technology in payments processes", Reserve Bank of New Zealand Bulletin, Vol. 81, No. 5, May.

Walch, A. (2019). "Deconstructing 'decentralization': exploring the core claim of crypto systems”, in C. Brummer (ed.), Cryptoassets: legal and monetary perspectives, Oxford University Press.

Woolard, C. (2019). "Regulating financial innovation - going behind the scenes", speech, 2 July.

WSJ (2009). "Paul Volcker: Think More Boldly", 13 December.

Zetzsche, D., D. Arner and R. Buckley (2020a). "Decentralised Finance”, Journal of Financial Regulation.

Zetzsche, D., W. Birdthistle, D. Arner and R. Buckley (2021). "Digital Finance Platforms: Toward a New Regulatory Paradigm", University of Pennsylvania Journal of Business Law.

Zetzsche, D., R. Buckley and D. Arner (2018). “The Distributed Liability of Distributed Ledgers: Legal Risks of Blockchain”, University of Illinois Law Review, No. 101.

- (2020b). "Regulating Libra: The Transformative Potential of Facebook's Cryptocurrency and Possible Regulatory Responses", Oxford Journal of Legal Studies. 
